\title{
Crossroads between nature and culture: an introduction
}

\author{
Giorgio Bernardi • Bernardino Fantini • \\ Ariane Dröscher
}

Received: 30 August 2014/ Accepted: 9 September 2014

(C) Springer International Publishing AG 2014

This tribute is a modest but deeply felt homage to Christiane Groeben, "the historical memory" of the Stazione Zoologica Anton Dohrn. The work she has done over 45 years is a fundamental contribution to the history of the Stazione and to the history of biology. The debt that we all owe to her is multilayered, as a developing organism. At the inner layer we find her long and hard work as an archivist at the Stazione, which has made available to scholars a huge amount of relevant archives (manuscripts, correspondence, administrative documentation, photos) of an invaluable utility for a great number of historians and philosophers of biology as well as for art historians and historians of scientific institutions. In the intermediate layer we find her methodological and stringent lesson on the use of archival sources: each document is a fact, a fundamental starting point for each historical reconstruction, but at the same time this fact always needs a theory to be explained and accurately placed within a rational reconstruction of the past.

Finally, the external and most apparent layer is anchored to Christiane's own research and publications, that have contributed to a deep knowledge of one of the most fantastic scientific enterprises, the creation of the Zoological Station, and to a better understanding of the personality of its creator, Anton Dohrn. If Dohrn's activity as a scientific manager and a biologist has been adequately described by

\footnotetext{
G. Bernardi $(\bowtie)$

Dipartimento di Scienze, Università Roma Tre, 446, Viale Marconi, 00146 Rome, Italy

e-mail: giorgio.bernardi@uniroma3.it

B. Fantini

Institut d'histoire de la médecine et de la santé, Université de Genève, 1211 Geneva 4, Switzerland e-mail: Bernardino.Fantini@unige.ch
}

\footnotetext{
A. Dröscher

Dipartimento di Storia, Culture, Civiltà, Università degli Studi di Bologna, Bologna, Italy

e-mail: coraariane.droscher@unibo.it
} 
other historians (e.g. Heuss 1962, 1991; Müller 1976; Dohrn and Ghiselin 1994; Maienschein 1994; Ghiselin and Groeben 1997; Fantini 1999, 2000; Bernardi 20092010), we owe to Christiane a careful analysis, based on personal accounts from the Archives of the Stazione, of the development of Anton Dohrn's personality, his inner motivations, his personal experiences, and the external factors and traditions. Dohrn is remembered largely as an organizer and administrator but he was also "a catalyst in the encouragement and stimulation of creative ideas" (Müller 1996, 103) and Groeben's analysis shows that Dohrn was in fact a creative thinker and a dreamer, able to build an international institution on solid grounds, to produce thorough and original scientific research and to make strong efforts to unify in the daily life of the Stazione science, art and music, producing a special "creative atmosphere", noted and signaled by all the guests of the new institution.

The originality of this vision went as far as choosing marine biodiversity in order to study evolution, and linking art and science to inspire creativity in research (Groeben 1985, 2001). The latter point is evident in what is the heart of the Stazione, the Fresco Room. During the summer of 1873 this room was decorated by the German sculptor and architect Adolf von Hildebrand and by the German painter Hans von Marées, who depicted a cycle of frescoes with scenes from Mediterranean life: fishermen, Dohrn and his friends relaxing after a hard day's work, orange groves with children, men and women (Ritter Santini and Groeben 2008). Anybody seeing for the first time this room cannot escape the feeling of being in a special place, "a sacred place for the biologist" (as François Jacob defined it at the time of the inauguration of the Laboratory of Molecular Evolution in 1998).

The Stazione Zoologica is the only scientific institution at which, from the very beginning, science, music and art were integral components of a common project, the two complementary halves of a unique dream. Nature and culture formed a coherent and organized whole, defining together the "soul", the essence of the Stazione. The guests and visitors of the Zoological Station thus experienced science and art as the two complementary sides of European culture (Groeben 1985).

The authors paying here their tribute to Christiane have not been invited to write on the nature-culture relationship. Therefore, it is even more significant that nearly all have developed their topic into this direction. Indeed, in her researches as well as in her hosting of persons and events at the Stazione, Christiane has always tried to bridge the laboratory-field divide as well as the (supposed) dichotomies between nature and culture and between science and arts, even in times when these categories were still en vogue. The more recent decades of history, philosophy and sociology of science have given here right. The interplays and the common spaces between nature and culture, between science and arts has become a fascinating though rocky field of study. Mostly, they rely on indirect, subliminal links, which are often not even detected by the scientist him/herself. Many scientists however, reflected on their source of inspiration; Anton Dohrn, for instance, as Fantini reports in his essay. Dohrn considered phylogeny a subtle thing that "wants not only the analytic powers of the researcher, but also the constructive imagination of the artist". The great challenge for historians, sociologists and philosophers is hence to go beyond the intuitive grasp. 
The main focus of this volume is of course on the biological sciences, with an special eye on the contributions of the Stazione Zoologica and of Anton Dohrn himself, in particular evolution and Darwinism (Ayala; Browne; Caianiello; Ghiselin; Hopwood; Levit, Hossfeld and Olsson), marine biology (Benson), embryology and development (Fantini; Levit, Hossfeld and Olsson), heredity (Dröscher; Volpone), and experimentation (Rheinberger; Volpone).

Whereas Francisco Ayala furnishes an overarching view, Michael Ghiselin insists that Darwin's enterprise, as well as Dohrn's Stazione, must both be regarded and treated as cosmopolitan. In fact, the essays that treat less known actors like Adolf Naef, Alexei Sewertzoff, Carlo Emery and Paolo Della Valle highlight the multilayered nature of the evolutionary debate, on the personal as well as on the scientific level. Dohrn's "principle of succession of functions" (Caianiello), Sewertzoff's idea of evolutionary plasticity of all stages of embryonic development (Levit, Hossfeld and Olsson), and Emery's concept of zymoplasm (Dröscher), all represent well-grounded alternative views of specific but fundamental aspects of the Darwinian framework, that were or still are ignored by most historians. Finally, Hans-Jörg Rheinberger reminds us not to forget the material dimension of scientific disputes, in particular the role of preparations (or specimen), models, and simulations, and Alessandro Volpone shows how the laboratory practice of chromosome counting influenced the way of conceiving heredity.

Great emphasis is however laid on the link between science and culture. On the one hand, this is exemplified by special relations the Dohrn family maintained with many eminent non-scientific personalities of their times. These cultural contacts were anything but secondary for Dohrn, as Irmgard Müller points out for the taut relationship between Anton Dohrn and the Krupp family, and Antonio Borelli shows for the case of the friendship between Reinhard Dohrn and Benedetto Croce. Moreover, these complex institutional and personal ties between science, philosophy, industry, and politics often turned out to be of crucial importance during politically and economically turbulent periods. The role of direct personal relationships and discussions is also at the center of the essays of Janet Browne (Anton Dohrn and Charles Darwin), of Georgy Levit, Uwe Hossfeld and Lennart Olsson (Alexei Sewertzoff and Adolf Naef), and Ariane Dröscher (August Weismann and Carlo Emery).

On the other hand, exactly this crossroad between science and culture is considered as imperative. Janet Browne insists that Darwinism must be seen as a social as well as a scientific enterprise. Levit, Hossfeld and Olsson stress the importance of the 'artistic intuition' for Sewertzoff's grasping of the development of forms, and Rheinberger suggests to understand the nature of scientific preparations and scientific modeling with an analogy between science and architecture.

Other authors dare to penetrate still deeper, making exactly this interspace their object of inquiry. Nick Hopwood's analysis of the satiric songs, rhymes and cartoons on Ernst Haeckel's celebration of Amphioxus as the primitive ancestor of all vertebrates, highlights the role of humour in negotiating evolution. These rhymes were characterized by good levels of scientific knowledge, of reference towards the "high priests" of science and of subtle but piercing critique. Keith Benson investigates how the choice of the actual place of practice of intertidal ecology 
research was driven by the aesthetic aspect. More than just the pleasure to work in and about beautiful landscapes, he argues, the aesthetic experience of the participant observer is an attempt to "break through" to an intuitive understanding of nature's patterns. Patterns are central for Bernardino Fantini's essay, too. He reveals common images and interpretive models in biology, medicine and music, in particular in their meditations on form and development, from Beethoven to Schönberg and from Kant to Dohrn.

\section{References}

Bernardi, G. (2009-2010). "Anton Dohrn e la Stazione Zoologica di Napoli”. Atti dell'Istituto Veneto di Scienze, Lettere ed Arti, 168: 55-64.

Dohrn, A., \& Ghiselin, M. T. (1994). The origin of vertebrates and the principle of succession of functions: Genealogical sketches. History and Philosophy of the Life Sciences, 16, 3-96.

Fantini, B. (1999). "The history of the stazione zoologica Anton Dohrn: An outline", In Stazione Zoologica Anton Dohrn. Activity Report 1998/1999, Naples: ImPrint, 71-107.

Fantini, B. (2000). The 'Stazione Zoologica Anton Dohrn' and the history of embryology. International Journal of Developmental Biology, 44, 523-535.

Ghiselin, M. T., \& Groeben, C. (1997). Elias Metschnikoff, Anton Dohrn, and the Metazoan Common Ancestor. Journal of the History of Biology, 30, 211-228.

Groeben, C. (1985). "Anton Dohrn: The Statesman of Darwinism”. Biological Bulletin, 168 (Suppl.): $4-25$.

Groeben, C. (2001). "La Stazione Zoologica Anton Dohrn”. In: La cultura scientifica e le sue istituzioni. Napoli 1860-1915, Napoli: Paparo Edizioni, 35-49.

Heuss, T. (1962). Anton Dohrn, erw. Neuaufl., Tübingen: Wunderlich. English edition: Heuss, T. (1991). Anton Dohrn. A Life for Science (ed: Groeben, C.). Berlin: Springer Verlag.

Maienschein, J. (1994). 'It's a long way from 'Amphioxus'. Anton Dohrn and late nineteenth century debates about vertebrate origins. History and Philosophy of the Life Sciences, 16, 465-478.

Müller, I. (1976). Die Geschichte der Zoologischen Station Neapel von der Gründung durch Anton Dohrn (1872) bis zum Ersten Weltkrieg und ihre Bedeutung für die Entwicklung der modernen biologischen Wissenschaften. Düsseldorf: Habilitations-Schrift, Universität Düsseldorf.

Müller, I. (1996). The impact of the Zoological Station in Naples on developmental physiology. International Journal of Developmental Biology, 10, 103-111.

Ritter Santini, L., Groeben, C. (Eds.), (2008). Art as Autobiography. Hans von Marées, Napoli: Gaetano Macchiaroli Editore. 